\title{
Stronger Correlation of Peak Oxygen Uptake With Distance of Incremental Shuttle Walk Test Than 6-minute Walk Test in Patients With COPD: a Systematic Review and Meta- analysis
}

\section{Ganghee Chae}

Asan Medical Center, University of Ulsan College of Medicine

\section{Eun Jae Ko}

Asan Medical Center, University of Ulsan College of Medicine

\section{Sei Won Lee}

Asan Medical Center, University of Ulsan College of Medicine

Hyun Jung Kim

College of Medicine, Korea University

\section{Sang Gyu Kwak}

College of Medicine, Catholic University of Daegu

\section{Donghwi Park}

Ulsan University Hospital, University of Ulsan College of Medicine

\section{Seung Won Ra ( $\nabla$ docra@docra.pe.kr)}

Ulsan University Hospital, University of Ulsan College of Medicine

\section{Research Article}

Keywords: exercise test, shuttle walk test, peak oxygen uptake, chronic obstructive pulmonary disease, meta-analysis

Posted Date: April 29th, 2021

DOI: https://doi.org/10.21203/rs.3.rs-457929/v1

License: (c) (i) This work is licensed under a Creative Commons Attribution 4.0 International License. Read Full License 


\section{Abstract}

Background: The 6-minute walk test (6MWT) and incremental shuttle walk test (ISWT) are valid and reliable measures to assess exercise capacity of patients with chronic obstructive pulmonary disease (COPD). However, the comparison of correlation between peak oxygen uptake (peak $\mathrm{VO}_{2}$ ) and 6MWT or ISWT distance has not been investigated. We aimed to investigate the correlation between peak $\mathrm{VO}_{2}$ and $6 \mathrm{MWT}$ and ISWT distances in patients with COPD through a metaanalysis.

Methods: We systematically searched MEDLINE, Scopus, Embase, and the Cochrane Library up to June 30, 2020 for studies comparing the correlation of peak $\mathrm{VO}_{2}$ with either 6MWT or ISWT in patients with COPD. Meta-analysis was performed with R software using a fixed-effect model. We compared the correlation coefficient and measured the heterogeneity using $\mathrm{I}^{2}$ statistics.

Results: We identified 12 studies involving 746 patients. Meta-analysis showed a significant correlation between peak $\mathrm{VO}_{2}$ and 6MWT and ISWT distances (6MWT: $r=0.65,95 \% \mathrm{Cl}: 0.61$ to 0.70 ; ISWT: $r=0.81,95 \% \mathrm{Cl}: 0.74$ to $0.85 ; p<$ 0.0001). The heterogeneity was lower in ISWT than in 6MWT (6MWT: $I^{2}=56 \%, p=0.02$; ISWT: $I^{2}=0 \%, p=0.71$ ). Subgroup analysis showed a higher correlation coefficient in the low exercise capacity group than in the high exercise capacity group in both field tests. No risk of publication bias was identified.

Conclusions: $6 \mathrm{MWT}$ and ISWT were significantly correlated with peak $\mathrm{VO}_{2}$. The findings suggest that ISWT had a stronger correlation with peak $\mathrm{VO}_{2}$ than did $6 \mathrm{MWT}$ in patients with COPD.

Trial registration: CRD 42020200139 at crd.york.ac.uk/prospero/

\section{Background}

Chronic obstructive pulmonary disease (COPD) is characterised by airflow limitation that is not fully reversible and often progressive. The airflow limitation is associated with an inflammatory response of the lungs, mainly caused by smoking. Cough, sputum, and dyspnea (upon exertion or at rest) are chronic manifestation of COPD as the disease progresses. Exercise limitation is also a prominent complaint in patients with COPD [1]. Therefore, to assess the functional capacity of patients with chronic airway obstruction, cardiopulmonary exercise testing (CPET) and field tests have been used. CPET provides a global assessment of the integrative exercise response involving the pulmonary, cardiovascular, hematopoietic, neuropsychologic, and skeletal muscle systems; thus, it has been regarded as a gold standard test to assess exercise capacity and response to therapeutic interventions in patients with COPD [2]. However, CPET requires the use of costly exercise equipment, trained technicians, and specialists to interpret the results. Furthermore, some COPD patients with severe dyspnea are unable to undergo tests with equipment measuring expired gas, such as a mouthpiece. Field tests are practical and simple; they do not require complex equipment that can hardly be tolerated or have difficult interpretation. In this regard, field tests, such as the 6-minute walk test (6MWT) and the incremental shuttle walk test (ISWT), and CPET are complementary. They play a key role in evaluating functional exercise capacity, assessing prognosis, and evaluating response to treatment $[3,4]$.

Walking distance during these field tests has been used to indicate the level of disability and cardiopulmonary capacity [5]. Peak oxygen uptake (peak $\mathrm{VO}_{2}$ ) is also regarded as an index of cardiopulmonary capacity, and air analysis during a maximal laboratory exercise test is the most precise method of measuring peak $\mathrm{VO}_{2}$ [6]. Previous studies showed a strong correlation between the distance of a field test and peak $\mathrm{VO}_{2}$ measured using CPET $[7,8]$.

6MWT is a practical and simple test that requires a patient to walk at the highest speed tolerated for 6 minutes. Therefore, 6MWT depends on individually adjusted characteristics, which are determined by patients who are even 
allowed to stop walking if they wish to [4]. By contrast, ISWT offers a different protocol from the 6MWT, which is incremental and externally paced. It is a 12-level test (1 minute at each level) that imposes incremental acceleration through an auditory signal used to control the pace on a 10-meter shuttle circuit delineated by two traffic cones. ISWT is also simple, has good reproducibility, and requires no specific ergometers [3, 9]. However, it has not been as widely accepted in clinical practice as 6MWT. To our knowledge, no study has compared the correlation between peak $\mathrm{VO}_{2}$ and 6MWT or ISWT distance. Therefore, in this study, we aimed to investigate the correlation between peak $\mathrm{VO}_{2}$ and $6 \mathrm{MWT}$ and ISWT distances in patients with COPD through a meta-analysis and compared the correlation coefficient for assessing the validity of the $6 \mathrm{MWT}$ and ISWT to predict peak $\mathrm{VO}_{2}$.

\section{Methods}

\section{Protocol and registration}

This meta-analysis was reported in accordance with the Preferred Reporting Items for Systematic Reviews and MetaAnalyses (PRISMA) statement [10]. The present study was registered in the PROSPERO international prospective register of systematic reviews (CRD 42020200139) and approved by the Institutional Review Board of Ulsan University Hospital (NON2020-001).

\section{Search strategy and selection criteria}

We systematically searched relevant studies published up to June 30, 2020 in MEDLINE, Scopus, Embase, and the Cochrane Library databases. The keywords were chosen by two physicians (GC and DP) and reviewed by keywords from other reviews and articles on similar topics. The following keywords were used to search the database: 'incremental shuttle walk test', ' 6 minute walk test', 'cardiopulmonary exercise testing', and 'chronic obstructive pulmonary disease'. Citations of published relevant systematic reviews and meta-analyses were examined to identify further pertinent studies, if any [7, 8]. Two articles published in Japan (written in Japanese) were included [11, 12].

Studies including patients with COPD who underwent CPET and either 6MWT or ISWT were selected. The inclusion criteria were as follows: (1) full-text original article; (2) studies on patients with COPD; (3) studies measuring peak $\mathrm{VO}_{2}$ using CPET; and (4) studies investigating the correlation between 6MWT and CPET or between ISWT and CPET. The exclusion criteria were as follows: (1) case reports, case series, and review articles; (2) studies that do not report extractable data available for independent parameters; (3) studies investigating only the correlation between 6MWT and ISWT; and (4) studies on patients with other lung diseases.

\section{Data extraction}

Data from included studies were independently extracted and assessed by two independent reviewers (GC and DP) using a standardised data collection form. Discrepancies were resolved by rechecking the source paper and further discussion amongst all authors. To investigate the correlations between peak $\mathrm{VO}_{2}$ and $6 \mathrm{MWT}$ distance or between peak $\mathrm{VO}_{2}$ and ISWT distance in patients with COPD, we divided the data extracted according to field test type (6MWT and ISWT).

We extracted the following data from eligible studies: surname of the first author, publication year, number of patients, sex ratio, mean age, the results of 6MWT and ISWT distances (meter), peak VO $2\left(\mathrm{ml} \bullet \mathrm{min}^{-1} \bullet \mathrm{kg}^{-1}\right.$ or $\left.\mathrm{ml}_{\bullet} \cdot \mathrm{min}^{-1}\right)$, the measurement property of peak $\mathrm{VO}_{2}$ in CPET, and the correlation coefficient between peak $\mathrm{VO}_{2}$ and distance of field test (6MWT or ISWT).

\section{Quality assessment}


The quality of included studies was assessed using the Methodological Index for Non-Randomized Studies (MINORS) [13]. Each study was assessed using eight criteria (maximum score 16): a clearly stated aim, inclusion of consecutive patients, prospective collection of data, endpoints appropriate to the aim of the study, unbiased assessment of the study endpoint, follow-up period appropriate to the aim of the study, loss to follow up less than $5 \%$, and prospective calculation of the study. The quality of each study was graded as not reported (0), reported but inadequate (1), and reported and adequate (2).

\section{Statistical analysis}

The R Statistics software version 4.0.2 (The R Foundation, Vienna, Austria) was used for statistical analysis of the pooled data. For the meta-analysis, the "meta" and "metafor" packages were used. We analysed the summary of correlation coefficient for validity assessment of $6 \mathrm{MWT}$ or ISWT to predict peak $\mathrm{VO}_{2}$. In each meta-analysis, $\mathrm{I}^{2}$ statistics was used to assess the heterogeneity, providing a measure of extent of inconsistency amongst results. Statistical significance was set at $\mathrm{p}$-value $<0.05$, and a $95 \%$ confidence interval $(\mathrm{Cl})$ was used. The risk of publication bias was determined using a funnel plot and the Egger's test. Since the included studies were relatively homogenous patients and estimated that the effect size of the population would be consistent, a fixed-effect model was used. Sensitivity analysis was performed using a random-effects model to explore the effects of computational model. Further, studies that conducted each one of 6MWT, ISWT, and CPET were analysed. Subgroup analysis was performed for exercise capacity of patients (according to the mean of peak $\mathrm{VO}_{2}$ ). We divided the patients with COPD into low or high exercise capacity group using the cut-off of the peak $\mathrm{VO}_{2}$ of $15 \mathrm{ml} \bullet \mathrm{min}^{-1} \bullet \mathrm{kg}^{-1}$ or $1000 \mathrm{ml} \bullet \mathrm{min}^{-1}[14,15]$.

\section{Results}

\section{Identification of relevant studies}

A total of 797 published studies were found after removing 358 duplicate articles from 1153 articles searched by keyword, and two additional articles were identified through other sources. Of the 797 retrieved articles, 12 studies were finally included in the meta-analysis after the inclusion and exclusion criteria were applied (Fig. 1) $[5,6,11,12,16-23]$.

\section{Study characteristics}

Study characteristics and detailed methodologies of included studies are reported in Tables 1 and 2. Twelve studies included a total of 746 patients with COPD, with individual sample size ranging from 13 to 209 . According to the type of field test, 10 studies reported correlation between peak $\mathrm{VO}_{2}$ and $6 \mathrm{MWT}$ distance and five studies reported correlation between peak $\mathrm{VO}_{2}$ and ISWT distance. 
Table 1

Characteristics of the included studies. reporting correlation between peak $\mathrm{VO}_{2}$ and $6 \mathrm{MWT}$ distance in patients with COPD $(n=10)$

\begin{tabular}{|c|c|c|c|c|c|c|c|c|c|}
\hline \multirow{2}{*}{$\begin{array}{l}\text { Study } \\
\text { [ref.] }\end{array}$} & \multirow[t]{2}{*}{ Year } & \multirow{2}{*}{$\begin{array}{l}\text { No. of } \\
\text { patients }\end{array}$} & \multirow{2}{*}{$\begin{array}{l}\text { Sex } \\
(M / F)\end{array}$} & \multirow{2}{*}{$\begin{array}{l}\text { Mean } \\
\text { age }\end{array}$} & \multirow{2}{*}{$\begin{array}{l}\text { 6MWT } \\
\text { distance } \\
\text { (m) }\end{array}$} & \multicolumn{2}{|l|}{ Peak VO 2} & \multirow{2}{*}{$\begin{array}{l}\text { CPET } \\
\text { measurement }\end{array}$} & \multirow{2}{*}{$\begin{array}{l}\text { Correlation } \\
\text { coefficient }\end{array}$} \\
\hline & & & & & & $\begin{array}{l}\left(\mathrm{ml} \cdot \mathrm{min}^{-}\right. \\
\left.1 \cdot \mathrm{kg}^{-1}\right)\end{array}$ & $\begin{array}{l}\left(\mathrm{ml} \cdot \mathrm{min}^{-}\right. \\
\left.{ }^{1}\right)\end{array}$ & & \\
\hline $\begin{array}{l}\text { Rejeski } \\
{[16]}\end{array}$ & 2000 & 209 & $117 / 92$ & $\begin{array}{l}67.2 \\
\pm 6.0\end{array}$ & $\begin{array}{l}474.9 \pm \\
105.2\end{array}$ & $\begin{array}{l}17.13 \pm \\
4.1\end{array}$ & & Treadmill & $0.64 \S$ \\
\hline $\begin{array}{l}\text { Chuang } \\
{[17]}\end{array}$ & 2001 & 27 & $27 / 0$ & $\begin{array}{l}65 \pm \\
6\end{array}$ & $\begin{array}{l}456.0 \pm \\
84.0\end{array}$ & $\begin{array}{l}18.9 \pm \\
5.0\end{array}$ & $\begin{array}{l}1110.0 \pm \\
350.0\end{array}$ & $\begin{array}{l}\text { Cycle } \\
\text { ergometer }\end{array}$ & $0.37 \S$ \\
\hline $\begin{array}{l}\text { Arizono } \\
{[11]}\end{array}$ & 2002 & 17 & $15 / 2$ & $\begin{array}{l}71.1 \\
\pm 4.3\end{array}$ & $\begin{array}{l}427.5 \pm \\
61.9\end{array}$ & $\begin{array}{l}15.2 \pm \\
2.8\end{array}$ & & Treadmill & $0.577 \S$ \\
\hline $\begin{array}{l}\text { Oga } \\
\text { [18] }\end{array}$ & 2002 & 36 & $36 / 0$ & $\begin{array}{l}69 \pm \\
7\end{array}$ & $\begin{array}{l}492.0 \pm \\
66.0\end{array}$ & $\begin{array}{l}15.6 \pm \\
3.7\end{array}$ & & $\begin{array}{l}\text { Cycle } \\
\text { ergometer }\end{array}$ & $0.64 \S$ \\
\hline $\begin{array}{l}\text { Carter } \\
\text { [19] }\end{array}$ & 2003 & 124 & $90 / 34$ & $\begin{array}{l}66.8 \\
\pm 7.3\end{array}$ & $\begin{array}{l}403.0 \pm \\
81.6\end{array}$ & & $\begin{array}{l}1095.6 \pm \\
323.5\end{array}$ & $\begin{array}{l}\text { Cycle } \\
\text { ergometer }\end{array}$ & $0.54^{\dagger}$ \\
\hline $\begin{array}{l}\text { Turner } \\
\text { [5] }\end{array}$ & 2004 & 20 & $15 / 5$ & $\begin{array}{l}64.0 \\
\pm 7.5\end{array}$ & $\begin{array}{l}474.9 \pm \\
87.8\end{array}$ & $\begin{array}{l}14.2 \pm \\
2.9\end{array}$ & & $\begin{array}{l}\text { Cycle } \\
\text { ergometer }\end{array}$ & $0.73 \S$ \\
\hline $\begin{array}{l}\text { Starobin } \\
{[20]}\end{array}$ & 2006 & 50 & $28 / 22$ & $\begin{array}{l}64.3 \\
\pm \\
11.7\end{array}$ & $\begin{array}{l}434.7 \pm \\
88.0\end{array}$ & $\begin{array}{l}13.5 \pm \\
4.1\end{array}$ & & $\begin{array}{l}\text { Cycle } \\
\text { ergometer }\end{array}$ & $0.58 \S$ \\
\hline $\begin{array}{l}\text { Arizono } \\
\text { [12] }\end{array}$ & 2008 & 100 & $91 / 9$ & $\begin{array}{l}69.6 \\
\pm 9.7\end{array}$ & $\begin{array}{l}479.7 \pm \\
122.5\end{array}$ & $\begin{array}{l}12.6 \pm \\
3.2\end{array}$ & & $\begin{array}{l}\text { Cycle } \\
\text { ergometer }\end{array}$ & $0.773 \S$ \\
\hline $\begin{array}{l}\text { Hill } \\
{[21]}\end{array}$ & 2008 & 50 & $36 / 14$ & $\begin{array}{l}68 \pm \\
8\end{array}$ & $\begin{array}{l}464.0 \pm \\
110.0\end{array}$ & & $\begin{array}{l}874.0 \pm \\
243.0\end{array}$ & $\begin{array}{l}\text { Cycle } \\
\text { ergometer }\end{array}$ & $0.63 \S$ \\
\hline $\begin{array}{l}\text { Díaz } \\
\text { [22] }\end{array}$ & 2010 & 81 & $49 / 32$ & $\begin{array}{l}67 \pm \\
8\end{array}$ & $\begin{array}{l}514.0 \pm \\
85.0\end{array}$ & $\begin{array}{l}16.5 \pm \\
4.0\end{array}$ & & $\begin{array}{l}\text { Cycle } \\
\text { ergometer }\end{array}$ & $0.78 \S$ \\
\hline \multicolumn{10}{|c|}{ Data are presented as mean \pm SD, unless otherwise stated. $\S$, Pearson's $r$; $\dagger$, Spearman's rho } \\
\hline $\begin{array}{l}\text { Abbreviat } \\
\text { disease; }\end{array}$ & $\begin{array}{l}\mathrm{s}: 6 \mathrm{M} \\
\mathrm{T}, \text { car }\end{array}$ & $\begin{array}{l}\text { 6-minu } \\
\text { ulmona }\end{array}$ & $\begin{array}{l}\text { valk tes } \\
\text { exercis }\end{array}$ & $\begin{array}{l}\text { eak V } \\
\text { st }\end{array}$ & eak ox & uptake; & D, chror & structive pulr & nary \\
\hline
\end{tabular}


Table 2

Characteristics of the included studies reporting correlation between peak $\mathrm{VO}_{2}$ and ISWT distance in patients with COPD $(n=5)$

\begin{tabular}{|c|c|c|c|c|c|c|c|c|}
\hline $\begin{array}{l}\text { Study } \\
\text { [ref.] }\end{array}$ & Year & $\begin{array}{l}\text { No. of } \\
\text { patients }\end{array}$ & $\begin{array}{l}\text { Sex } \\
(M / F)\end{array}$ & $\begin{array}{l}\text { Mean } \\
\text { age }\end{array}$ & $\begin{array}{l}\text { ISWT } \\
\text { distance } \\
\text { (m) }\end{array}$ & $\begin{array}{l}\text { Peak VO } \\
\\
\left(\mathrm{ml} \bullet \mathrm{min}^{-}\right. \\
\left.1 \cdot \mathrm{kg}^{-1}\right)\end{array}$ & $\begin{array}{l}\text { CPET } \\
\text { measurement }\end{array}$ & $\begin{array}{l}\text { Correlation } \\
\text { coefficient }\end{array}$ \\
\hline Singh [6] & 1994 & 19 & $17 / 2$ & $61 \pm 7$ & $\begin{array}{l}401.8 \pm \\
142.3\end{array}$ & $14.2 \pm 4.1$ & Treadmill & $0.88 \S$ \\
\hline $\begin{array}{l}\text { Arizono } \\
\text { [11] }\end{array}$ & 2002 & 17 & $15 / 2$ & $\begin{array}{l}71.1 \pm \\
4.3\end{array}$ & $\begin{array}{l}353.5 \pm \\
123.3\end{array}$ & $15.2 \pm 2.8$ & Treadmill & $0.776^{\S}$ \\
\hline $\begin{array}{l}\text { Onorati } \\
\text { [23] }\end{array}$ & 2003 & 13 & $13 / 0$ & $70 \pm 1$ & $\begin{array}{l}391.0 \pm \\
31.0\end{array}$ & $19.1 \pm 0.8$ & $\begin{array}{l}\text { Cycle } \\
\text { ergometer }\end{array}$ & $0.72 \S$ \\
\hline $\begin{array}{l}\text { Turner } \\
\text { [5] }\end{array}$ & 2004 & 20 & $15 / 5$ & $\begin{array}{l}64.0 \pm \\
7.5\end{array}$ & $\begin{array}{l}339.0 \pm \\
97.2\end{array}$ & $14.2 \pm 2.9$ & $\begin{array}{l}\text { Cycle } \\
\text { ergometer }\end{array}$ & $0.73^{\S}$ \\
\hline $\begin{array}{l}\text { Arizono } \\
\text { [12] }\end{array}$ & 2008 & 100 & $91 / 9$ & $\begin{array}{l}69.6 \pm \\
9.7\end{array}$ & $\begin{array}{l}378.2 \pm \\
152.2\end{array}$ & $12.6 \pm 3.2$ & $\begin{array}{l}\text { Cycle } \\
\text { ergometer }\end{array}$ & $0.813^{\S}$ \\
\hline
\end{tabular}

Data are presented as mean \pm SD, unless otherwise stated. §, Pearson's $r$

Abbreviations: ISWT, incremental shuttle walk test; peak $\mathrm{VO}_{2}$, peak oxygen uptake; $\mathrm{COPD}$, chronic obstructive pulmonary disease; CPET, cardiopulmonary exercise test

\section{Quality assessment}

In all included studies, 'a clearly stated aim', 'inclusion of consecutive patients', 'endpoints appropriate to the aim of the study', 'unbiased assessment of the study endpoint', and 'follow-up period appropriate to the aim of the study' were reported adequately. However, regarding 'prospective collection of data', only one study reported inappropriately. More than $5 \%$ loss to follow-up was reported in three studies. Any included studies did not calculate the appropriate sample size prior to the initiation of each study (Additional file 1).

\section{Meta-analysis results}

In patients with COPD who underwent CPET and 6MWT (10 studies, $n=714$ ), the 6MWT distance was a significant predictor of peak $\mathrm{VO}_{2}$ measured using CPET ( $r=0.65,95 \% \mathrm{Cl}: 0.61$ to 0.70$)$. In patients with COPD who underwent CPET and ISWT ( 5 studies, $n=169$ ), the ISWT distance was also a significant predictor of peak $\mathrm{VO}_{2}$ measured using CPET ( $r=$ $0.81,95 \% \mathrm{Cl}: 0.74$ to 0.85$)$. The heterogeneity was higher in $6 \mathrm{MWT}$ than in ISWT $\left(6 \mathrm{MWT}: \mathrm{I}^{2}=56 \% ; p=0.02, \mathrm{ISWT}: \mathrm{I}^{2}=0 \%\right.$; $\mathrm{p}=0.69)$ (Fig. 2).

Sensitivity analysis was conducted to evaluate the effects of computational model. The heterogeneity, pooled correlation coefficients, and $95 \% \mathrm{Cl}$ of the indexes remained stable and were not significantly altered by the random-effects model (6MWT: $r=0.65,95 \%$ Cl: 0.57 to 0.72 , ISWT: $r=0.81,95 \% \mathrm{Cl}: 0.74$ to $0.85 ; p<0.0001$ ) (Additional file 2). We performed sensitivity analysis on three studies that conducted each one of 6MWT, ISWT, and CPET. The ISWT also showed a stronger correlation than 6MWT (6MWT: $r=0.75 ; 95 \% \mathrm{Cl}: 0.66$ to 0.82 , ISWT: $r=0.80 ; 95 \% \mathrm{Cl}: 0.73$ to $0.85, p<0.0001$ ) (Additional file 3).

We performed a subgroup analysis for exercise capacity of patients with COPD according to the mean of peak $\mathrm{VO}_{2}$ : low exercise capacity group, peak $\mathrm{VO}_{2}<15 \mathrm{ml} \bullet \mathrm{min}^{-1} \bullet \mathrm{kg}^{-1}$ or $1000 \mathrm{ml} \bullet \mathrm{min}^{-1}$; and high exercise capacity group, peak $\mathrm{VO}_{2} \geq$ 
$15 \mathrm{ml} \bullet \mathrm{min}^{-1} \cdot \mathrm{kg}^{-1}$ or $1000 \mathrm{ml} \bullet \mathrm{min}^{-1}$. In both field tests, the correlation coefficient was higher in the low exercise capacity group than in the high exercise capacity group (low exercise capacity group: $r=0.70$ [6MWT], $r=0.81$ [ISWT]; $p=0.017$, high exercise capacity group: $r=0.63$ [6MWT], $r=0.75$ [ISWT]; $p=0.256$ ). The heterogeneity of $6 \mathrm{MWT}$ in the high exercise capacity group was higher than in the low exercise capacity group (low exercise capacity group: $I^{2}=43 \% ; p=0.15$, high exercise capacity group: $I^{2}=60 \% ; p=0.03$ ). The heterogeneity of ISWT was very low and consistent regardless of peak $\mathrm{VO}_{2}$ (low exercise capacity group: $\mathrm{I}^{2}=0 \% ; \mathrm{p}=0.44$, high exercise capacity group: $\mathrm{I}^{2}=0 \% ; \mathrm{p}=0.76$ ) (Fig. 3 )

\section{Publication bias}

A funnel plot was created to investigate the risk of publication bias. In patients with COPD who underwent CPET and $6 \mathrm{MWT}$, a funnel plot between peak $\mathrm{VO}_{2}$ and $6 \mathrm{MWT}$ distance showed some asymmetry. However, the Egger's test showed no statistical significance $(p=0.73)$. This findings indicates that the asymmetry observations were not supported and that there may be no risk of publication bias. In patients with COPD who underwent CPET and ISWT, a funnel plot between peak $\mathrm{VO}_{2}$ and ISWT distance showed symmetry. The Egger's test showed no statistical significance $(p=0.62)$, indicating that there may be no risk of publication bias (Fig. 4).

\section{Discussion}

Several studies have compared the correlation between peak $\mathrm{VO}_{2}$ and ISWT and 6MWT distances, but this study is the first to perform a meta-analysis of the correlation. This meta-analysis provided further evidence that the 6MWT and ISWT distances had significant correlations with peak $\mathrm{VO}_{2}$ measured using CPET in patients with COPD. When comparing the correlation coefficients with peak $\mathrm{VO}_{2}$, the ISWT showed a stronger correlation than the 6MWT. These results suggest that ISWT reflects a stronger correlation with peak $\mathrm{VO}_{2}$ measured using CPET than 6MWT in patients with COPD.

To date, many studies have confirmed that 6MWT and ISWT are valid, reliable, and responsive to therapeutic interventions $[8,24]$. However, the 6MWT and ISWT provide quite different protocols. The 6MWT is a self-paced submaximal test and can be continuous or intermittent. This test is sensitive to methodological variations, such as encouragement, oxygen supplement, and circumstances (e.g., wheeled walking aid, circular/straight track, indoors/outdoors) [24]. By contrast, ISWT is an externally paced maximal exercise test [5, 8, 24]. This feature may be an advantage in circumstances where methodological variation is a concern if the test is performed by various sites or operators [8]. In addition, where the larger space requirements of 6MWT preclude its use, ISWT can be a useful alternative [8]. 6MWT requires a 30-meter walking course, but ISWT only requires a short course of 10-meter walking course. The protocol of ISWT is more standardised than that of 6MWT, and the proposal of incremental values is also clear in the shuttle walk test. In addition, ISWT shows a linear change of lung gas exchange including peak $\mathrm{VO}_{2}$, but $6 \mathrm{MWT}$ shows an exponential change [23]. Furthermore, the walking distance in ISWT has been reported to be reliable and a good indicator for predicting re-hospitalisations in patients with moderate to severe COPD [25]. Therefore, ISWT has better features than 6MWT.

Thus, we aimed to determine the correlation between peak $\mathrm{VO}_{2}$ and 6MWT and ISWT distances through a meta-analysis and to compare the correlation coefficient of both field tests. In previous studies, both field tests were confirmed to show a relatively strong correlation with peak $\mathrm{VO}_{2}$ through a meta-analysis. Notably, the correlation coefficient of ISWT was stronger than that of 6MWT. In a subgroup analysis, we found that both field tests had lower correlation coefficients in the high exercise capacity group. That is, when the exercise capacity was good, the correlation between the distance of field tests and peak $\mathrm{VO}_{2}$ decreased. This may be related to the "ceiling effect" that occurred in 6MWT. In a related study comparing bronchodilator-induced changes in exercise capacity with the 6MWT and the shuttle walk test, 6MWT showed less responsive for detecting changes in COPD patients with high exercise capacity [26]. In addition, the heterogeneity of ISWT was very low in all analyses. Although there was a limitation to the small number of the included ISWT studies, the 
low heterogeneity could support the good reproducibility of ISWT. On the contrary, 6MWT showed high heterogeneity, and

$\mathrm{I}^{2}$ value was higher, particularly in the high exercise capacity group. ISWT was proven superior to 6MWT for evaluating COPD patients with high exercise capacity.

Despite the advantages of ISWT, it is underutilised to evaluate exercise capacity and effectiveness for treatment and respiratory rehabilitation, and to predict prognosis in chronic respiratory diseases. Many studies have already demonstrated its superiority in pre-operation evaluation, respiratory rehabilitation, and cardiopulmonary function evaluation [24, 27-29]. ISWT has not been introduced in many countries including South Korea. 6MWT is also a good field test [4]. However, considering the result of this study and other studies,[5, 6, 11, 12, 23] the use of ISWT is recommended because a stronger correlation with peak $\mathrm{VO}_{2}$ in CPET was found in this study using a meta-analysis.

This systematic review and meta-analysis has several limitations that should be mentioned. Firstly, we only included a small number of studies. Secondly, in the included studies, exercise modalities in CPET were heterogeneous. Peak $\mathrm{VO}_{2}$ was measured using a treadmill in three studies and a cycle ergometer in nine studies. Several studies have reported that the peak $\mathrm{VO}_{2}$ measured using a cycle ergometer is lower than that using a treadmill, but both peak $\mathrm{VO}_{2}$ measured with these devices show a significant correlation $[30,31]$. In addition, the objective of this study was not to analyse the absolute value of the peak $\mathrm{VO}_{2}$, but to investigate the correlation between the peak $\mathrm{VO}_{2}$ and the field test results. Therefore, the difference in CPET exercise method is believed to not significantly affect the results of this study. Finally, for more convincing evidence with regard to the correlation between peak $\mathrm{VO}_{2}$ and field tests, more qualified prospective studies are required. In addition, future studies should verify whether the correlation coefficient of ISWT is superior to that of $6 \mathrm{MWT}$ as a primary outcome after calculating the sample size with the superiority study design.

\section{Conclusions}

The present study found further evidence that 6MWT and ISWT correlated significantly with peak $\mathrm{VO}_{2}$ measured using CPET in patients with COPD through a meta-analysis. In addition, the ISWT distance showed a stronger correlation with peak $\mathrm{VO}_{2}$ than did the $6 \mathrm{MWT}$ distance as expected, suggesting that ISWT is more valid and reliable to assess maximal exercise capacity in patients with COPD.

\section{Declarations}

Ethics approval and consent to participate: The present study was approved by the Institutional Review Board of Ulsan University Hospital (NON2020-001).

Consent for publication: Not applicable

Availability of data and materials: The datasets used and/or analysed during the current study are available from the corresponding author on reasonable request.

Competing interests: The authors declare that they have no competing interests.

\section{Funding: None}

Authors' contributions: GC enriched the conception, conducted literature search, assessed the studies, and wrote the first draft of the manuscript. EJK and SWL commented on the earlier drafts of the manuscript and approved the final manuscript. HJK and SGK commented the methodology. DP initiated the conception of this review, conducted literature search, assessed the studies, and revised the final manuscript. SWR initiated the conception of this review, directed the design, and approved the final manuscript. All the authors read and approved the final manuscript. 
Acknowledgements: The authors would like to thank Yangjin Jegal, Taehoon Lee, Byung Ju Kang, and Jin Hyoung Kim (Ulsan University Hospital) for giving valuable comments at the research meeting.

\section{References}

1. Celli BR, MacNee W, ATS/ERS Task Force. Standards for the diagnosis and treatment of patients with COPD: a summary of the ATS/ERS position paper. Eur Respir J. 2004;23:932-46.

2. American Thoracic Society, American College of Chest Physicians. ATS/ACCP statement on cardiopulmonary exercise testing. Am J Respir Crit Care Med. 2003;167:211-77.

3. Singh SJ, Morgan MD, Scott S, Walters D, Hardman AE. Development of a shuttle walking test of disability in patients with chronic airways obstruction. Thorax. 1992;47:1019-24.

4. ATS Committee on Proficiency Standards for Clinical Pulmonary Function Laboratories. ATS statement: guidelines for the six-minute walk test. Am J Respir Crit Care Med. 2002;166:111-7.

5. Turner SE, Eastwood PR, Cecins NM, Hillman DR, Jenkins SC. Physiologic responses to incremental and self-paced exercise in COPD: a comparison of three tests. Chest. 2004;126:766-73.

6. Singh SJ, Morgan MD, Hardman AE, Rowe C, Bardsley PA. Comparison of oxygen uptake during a conventional treadmill test and the shuttle walking test in chronic airflow limitation. Eur Respir J. 1994;7:2016-20.

7. Parreira VF, Janaudis-Ferreira T, Evans RA, Mathur S, Goldstein RS, Brooks D. Measurement properties of the incremental shuttle walk test. a systematic review. Chest. 2014;145:1357-69.

8. Singh SJ, Puhan MA, Andrianopoulos V, Hernandes NA, Mitchell KE, Hill CJ, et al. An official systematic review of the European Respiratory Society/American Thoracic Society: measurement properties of field walking tests in chronic respiratory disease. Eur Respir J. 2014;44:1447-78.

9. Elías Hernández MT, Fernández Guerra J, Toral Marín J, Ortega Ruiz F, Sánchez Riera H, Montemayor Rubio T. Reproducibility of a shuttle walking test in patients with chronic obstructive pulmonary disease. Arch Bronconeumol. 1997;33:64-8.

10. Moher D, Liberati A, Tetzlaff J, Altman DG, The PRISMA Group. Preferred reporting items for systematic reviews and meta-analyses: the PRISMA statement. PLoS Med. 2009;6:e1000097.

11. Arizono S-i, Kitagawa C, Tanaka T, Oike T, Rikitomi N, Takahashi T, et al. Validity of incremental shuttle walking test as a measure of exercise tolerance in chronic obstructive pulmonary disease. Journal of Japan Society for Respiratory Care. 2002;11:414-9.

12. Arizono S-i, Ogawa T, Watanabe F, Homon R, Hirasawa J, Kondoh Y, et al. Prediction of peak $\mathrm{VO}_{2}$ using 6 minutes walk test and incremental shuttle walking test in COPD patients. Journal of Japan Society for Respiratory Care. 2008;18:160-5.

13. Slim K, Nini E, Forestier D, Kwiatkowski F, Panis Y, Chipponi J. Methodological index for non-randomized studies (MINORS): development and validation of a new instrument. ANZ J Surg. 2003;73:712-6.

14. Oga T, Nishimura K, Tsukino M, Sato S, Hajiro T. Analysis of the factors related to mortality in chronic obstructive pulmonary disease: role of exercise capacity and health status. Am J Respir Crit Care Med. 2003;167:544-9.

15. Hiraga T, Maekura R, Okuda Y, Okamoto T, Hirotani A, Kitada S, et al. Prognostic predictors for survival in patients with COPD using cardiopulmonary exercise testing. Clin Physiol Funct Imaging. 2003;23:324-31.

16. Rejeski WJ, Foley KO, Woodard CM, Zaccaro DJ, Berry MJ. Evaluating and understanding performance testing in COPD patients. J Cardiopulm Rehabil. 2000;20:79-88.

17. Chuang ML, Lin IF, Wasserman K. The body weight-walking distance product as related to lung function, anaerobic threshold and peak $\mathrm{VO}_{2}$ in COPD patients. Respir Med. 2001;95:618-26. 
18. Oga T, Nishimura K, Tsukino M, Hajiro T, Ikeda A, Mishima M. Relationship between different indices of exercise capacity and clinical measures in patients with chronic obstructive pulmonary disease. Heart Lung. 2002;31:374-81.

19. Carter R, Holiday DB, Nwasuruba C, Stocks J, Grothues C, Tiep B. 6-minute walk work for assessment of functional capacity in patients with COPD. Chest. 2003;123:1408-15.

20. Starobin D, Kramer MR, Yarmolovsky A, Bendayan D, Rosenberg I, Sulkes J, et al. Assessment of functional capacity in patients with chronic obstructive pulmonary disease: correlation between cardiopulmonary exercise, 6 minute walk and 15 step exercise oximetry test. Isr Med Assoc J. 2006;8:460-3.

21. Hill K, Jenkins SC, Cecins N, Philippe DL, Hillman DR, Eastwood PR. Estimating maximum work rate during incremental cycle ergometry testing from six-minute walk distance in patients with chronic obstructive pulmonary disease. Arch Phys Med Rehabil. 2008;89:1782-7.

22. Díaz O, Morales A, Osses R, Klaassen J, Lisboa C, Saldías F. Six-minute-walk test and maximum exercise test in cycloergometer in chronic obstructive pulmonary disease. Are the physiological demands equivalent? Arch Bronconeumol. 2010;46:294-301.

23. Onorati P, Antonucci R, Valli G, Berton E, De Marco F, Serra P, et al. Non-invasive evaluation of gas exchange during a shuttle walking test vs. a 6-min walking test to assess exercise tolerance in COPD patients. Eur J Appl Physiol. 2003;89:331-6.

24. Holland AE, Spruit MA, Troosters T, Puhan MA, Pepin V, Saey D, et al. An official European Respiratory Society/American Thoracic Society technical standard: field walking tests in chronic respiratory disease. Eur Respir J. 2014;44:1428-46.

25. Emtner MI, Arnardottir HR, Hallin R, Lindberg E, Janson C. Walking distance is a predictor of exacerbations in patients with chronic obstructive pulmonary disease. Respir Med. 2007;101:1037-40.

26. Pepin V, Brodeur J, Lacasse Y, Milot J, Leblanc P, Whittom F, et al. Six-minute walking versus shuttle walking: responsiveness to bronchodilation in chronic obstructive pulmonary disease. Thorax. 2007;62:291-8.

27. Morales FJ, Martínez A, Méndez M, Agarrado A, Ortega F, Fernández-Guerra J, et al. A shuttle walk test for assessment of functional capacity in chronic heart failure. Am Heart J. 1999;138:291-8.

28. Mador MJ, Modi K. Comparing various exercise tests for assessing the response to pulmonary rehabilitation in patients with COPD. J Cardiopulm Rehabil Prev. 2016;36:132-9.

29. Brunelli A, Kim AW, Berger KI, Addrizzo-Harris DJ. Physiologic evaluation of the patient with lung cancer being considered for resectional surgery: diagnosis and management of lung cancer, 3rd ed: American College of Chest Physicians evidence-based clinical practice guidelines. Chest. 2013;143:e166S-e90S.

30. Mays RJ, Boér NF, Mealey LM, Kim KH, Goss FL. A comparison of practical assessment methods to determine treadmill, cycle, and elliptical ergometer $\mathrm{VO}_{2}$ peak. J Strength Cond Res. 2010;24:1325-31.

31. Loftin $\mathrm{M}$, Sothern $\mathrm{M}$, Warren $\mathrm{B}$, Udall J. Comparison of $\mathrm{VO}_{2}$ peak during treadmill and cycle ergometry in severely overweight youth. J Sports Sci Med. 2004;3:554-60.

\section{Figures}




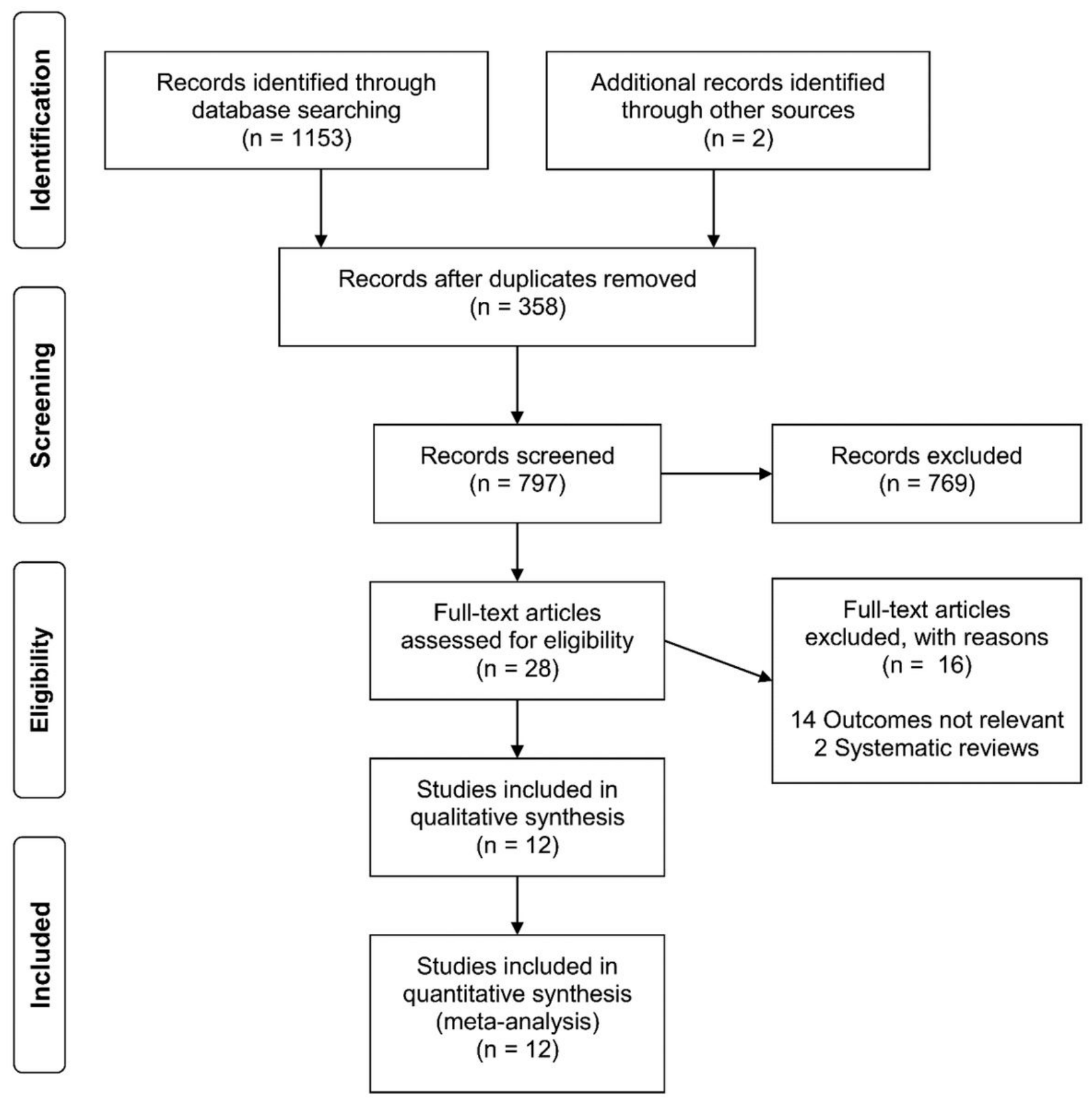

Figure 1

Preferred reporting items for systematic reviews and meta-analyses flow diagram for the identification of studies included in the meta-analysis about the correlation between peak VO2 and 6MWT and ISWT distances in patients with COPD Abbreviations: peakV02, peak oxygen uptake; 6MWT, 6-minute walk test; ISWT, incremental shuttle walk test; COPD, chronic obstructive pulmonary disease 


\section{MWT \& peak $\mathrm{VO}_{2}$}

Study

Rejeski et al. (2000)

Chuang et al. (2001)

Arizono et al. (2002)

Oga et al. (2002)

Carter et al. (2003)

Turner et al. (2004)

Starobin et al. (2006)

Arizono et al. (2008)

Hill et al. (2008)

Diaz et al. (2010)

Fixed effect model

Heterogeneity: $R^{2}=56 \%, \tau^{2}=0.0198, p=0.02$

Total

209

27

17

36

124

20

50

100

50

81

714
Correlation

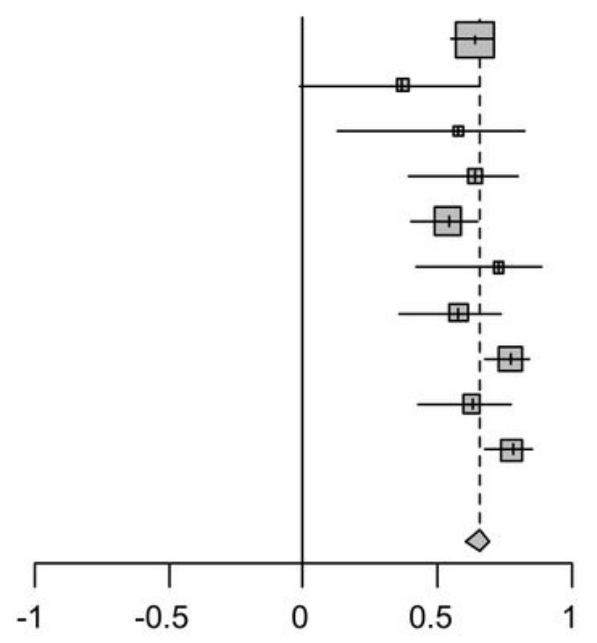

COR $\quad 95 \%-\mathrm{Cl}$ Weight

$0.64[0.55 ; 0.71] \quad 30.1 \%$

$0.37[-0.01 ; 0.66] \quad 3.5 \%$

$0.58 \quad[0.13 ; 0.83] \quad 2.0 \%$

$0.64[0.39 ; 0.80] \quad 4.8 \%$

$0.54 \quad[0.40 ; 0.65] \quad 17.7 \%$

$0.73 \quad[0.42 ; 0.89] \quad 2.5 \%$

$0.58 \quad[0.36 ; 0.74] \quad 6.9 \%$

$0.77 \quad[0.68 ; 0.84] \quad 14.2 \%$

$0.63[0.43 ; 0.77] \quad 6.9 \%$

$0.78 \quad[0.68 ; 0.85] \quad 11.4 \%$

$0.65[0.61 ; 0.70] \quad 100.0 \%$

b

$\begin{array}{lc}\text { Study } & \text { Total } \\ \text { Singh et al. (1994) } & 19 \\ \text { Arizono et al. (2002) } & 17 \\ \text { Onorati et al. (2003) } & 13 \\ \text { Turner et al. (2004) } & 20 \\ \text { Arizono et al. (2008) } & 100 \\ \text { Fixed effect model } & \mathbf{1 6 9} \\ \text { Heterogeneity: } P^{2}=0 \%, \tau^{2}=0, p=0.69\end{array}$

\section{ISWT \& peak $\mathrm{VO}_{2}$}

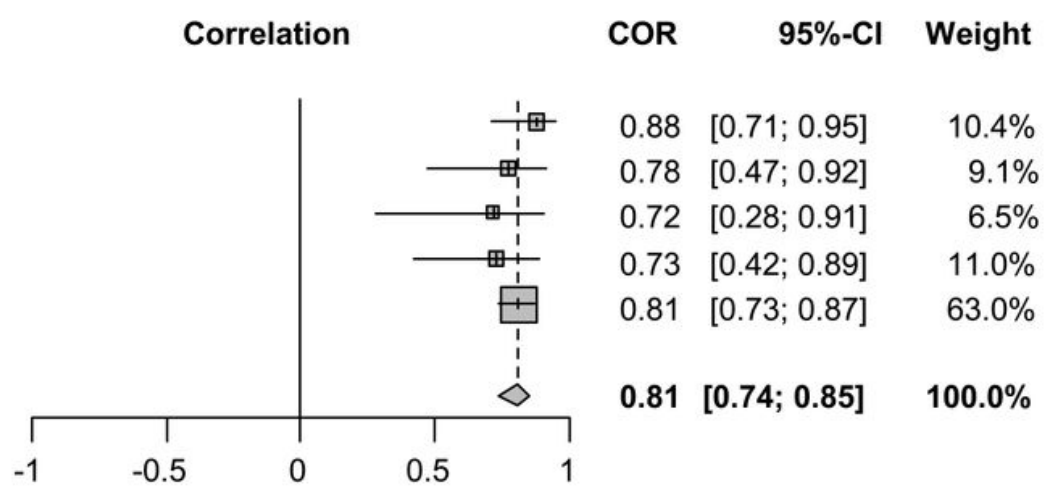

Figure 2

Forest plot of meta-analysis Meta-analysis was performed in (A) 10 studies assessing the correlation coefficient between peak VO2 and distance of the 6MWT and in (B) five studies assessing the correlation coefficient between peak VO2 and ISWT distance. Abbreviations: 6MWT, 6-minute walk test; peak V02, peak oxygen uptake; ISWT, incremental shuttle walk test 
6MWT

\section{Study}

Peak $\mathrm{VO}_{2}<15 \mathrm{ml} \cdot \mathrm{min}^{-1} \cdot \mathrm{kg}^{-1}$ (Low exercise capacity)

Turner et al. (2004)

Starobin et al. (2006)

Arizono et al. (2008)

Hill et al. (2008) \#

Fixed effect model

Heterogeneity: $R=43 \%, \tau^{2}=0.0162, p=0.15$

Peak $\mathrm{VO}_{2} \geq 15 \mathrm{ml} \cdot \mathrm{min}^{-1} \cdot \mathrm{kg}^{-1}$ (High exercise capacity)

Rejeski et al. (2000)

Chuang et al. (2001)

Arizono et al. (2002)

Oga et al. (2002)

Carter et al. (2003) \#

Diaz et al. (2010)

Fixed effect model

Heterogeneity: $R=60 \%, \tau^{2}=0.0225, p=0.03$

Fixed effect model

714

Heterogeneity: $R=43 \%, \tau^{2}=0.0162, p=0.15$

\section{Correlation}

$0.64[0.55 ; 0.71]$

$0.37[-0.01 ; 0.66]$

$0.58[0.13 ; 0.83]$

$0.64[0.39 ; 0.80]$

$0.54[0.40 ; 0.65]$
$0.78 \quad[0.68 ; 0.85]$

$0.63[0.57 ; 0.68]$

$0.65[0.61 ; 0.70]$

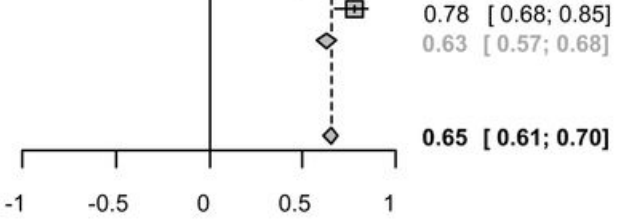

$2.5 \%$

$6.9 \%$

$14.2 \%$

$6.9 \%$

$30.4 \%$

$30.1 \%$

$3.5 \%$

$2.0 \%$

$4.8 \%$

$17.7 \%$

$11.4 \%$

$69.6 \%$

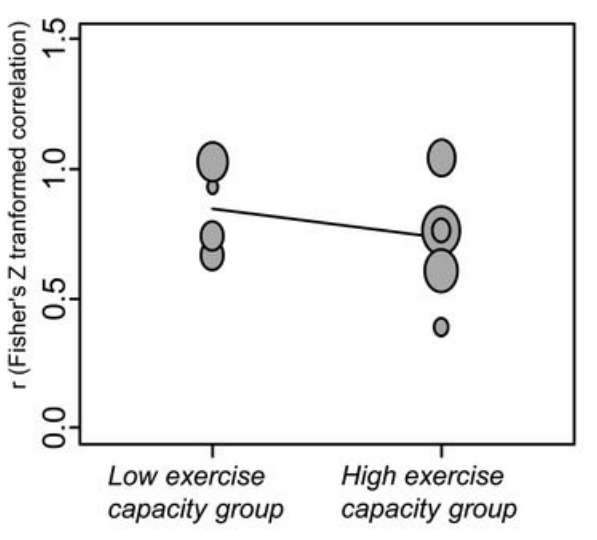

$100.0 \%$

b

\section{ISWT}

Study

Total

Peak $\mathrm{VO}_{2}<15 \mathrm{ml} \cdot \mathrm{min}^{-1} \cdot \mathrm{kg}^{1}$ (Low exercise capacity)

Singh et al. (1994)

Turner et al. (2004)

Arizono et al. (2008) 100

Fixed effect model $\quad 139$

Heterogeneity: $R=0 \%, \tau^{2}=0, p=0.44$

Peak $\mathrm{VO}_{2} \geq 15 \mathrm{ml} \cdot \mathrm{min}^{-1} \cdot \mathrm{kg}^{1}$ (High exercise capacity)

Arizono et al. (2002)

Onorati et al. (2003)

Fixed effect model

Heterogeneity: $R=0 \%, \tau^{2}=0, p=0.76$

Fixed effect model

169

Heterogeneity: $R=0 \%, \tau^{2}=0, p=0.69$

$\begin{array}{ll}-1 & \text { (Low exercise capacity) } \\ 19 & \\ 20 & \\ 00 & \\ 9 & \end{array}$

\section{7}

13

(3)

\section{9}

Her
(High exercise capacity)

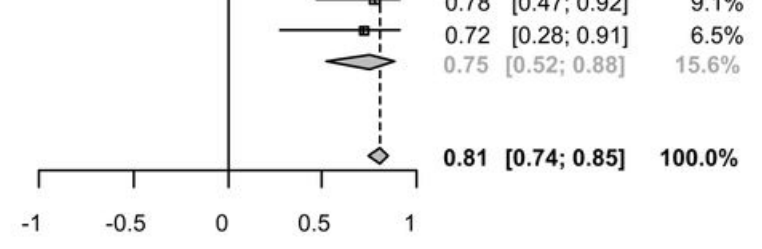

COR $95 \%-C I$ Weight

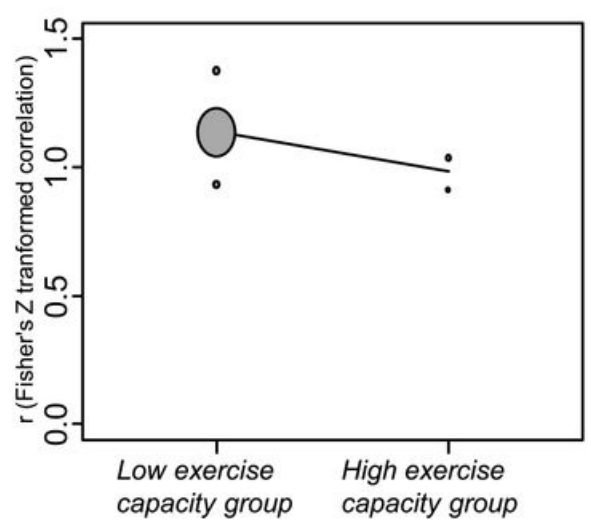

Figure 3

Forest plot and bubble plot of subgroup analysis divided by exercise capacity \#: In this study, we used the cut-off of the peak VO2 for 1000 ml•min-1. Abbreviations: 6MWT, 6-minute walk test; peak V02, peak oxygen uptake; ISWT, incremental shuttle walk test 
6MWT \& peak $\mathrm{VO}_{2}$

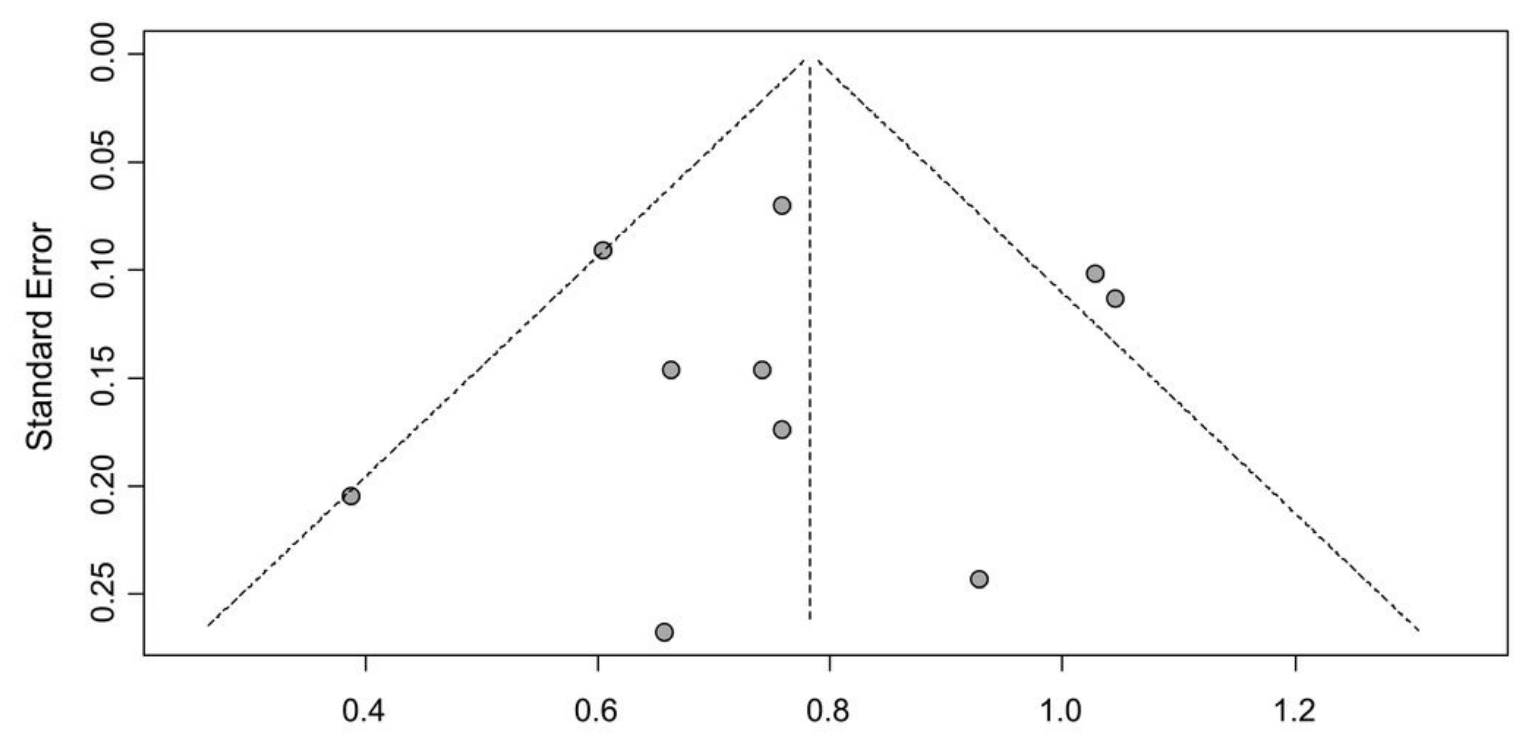

b

ISWT \& peak $\mathrm{VO}_{2}$

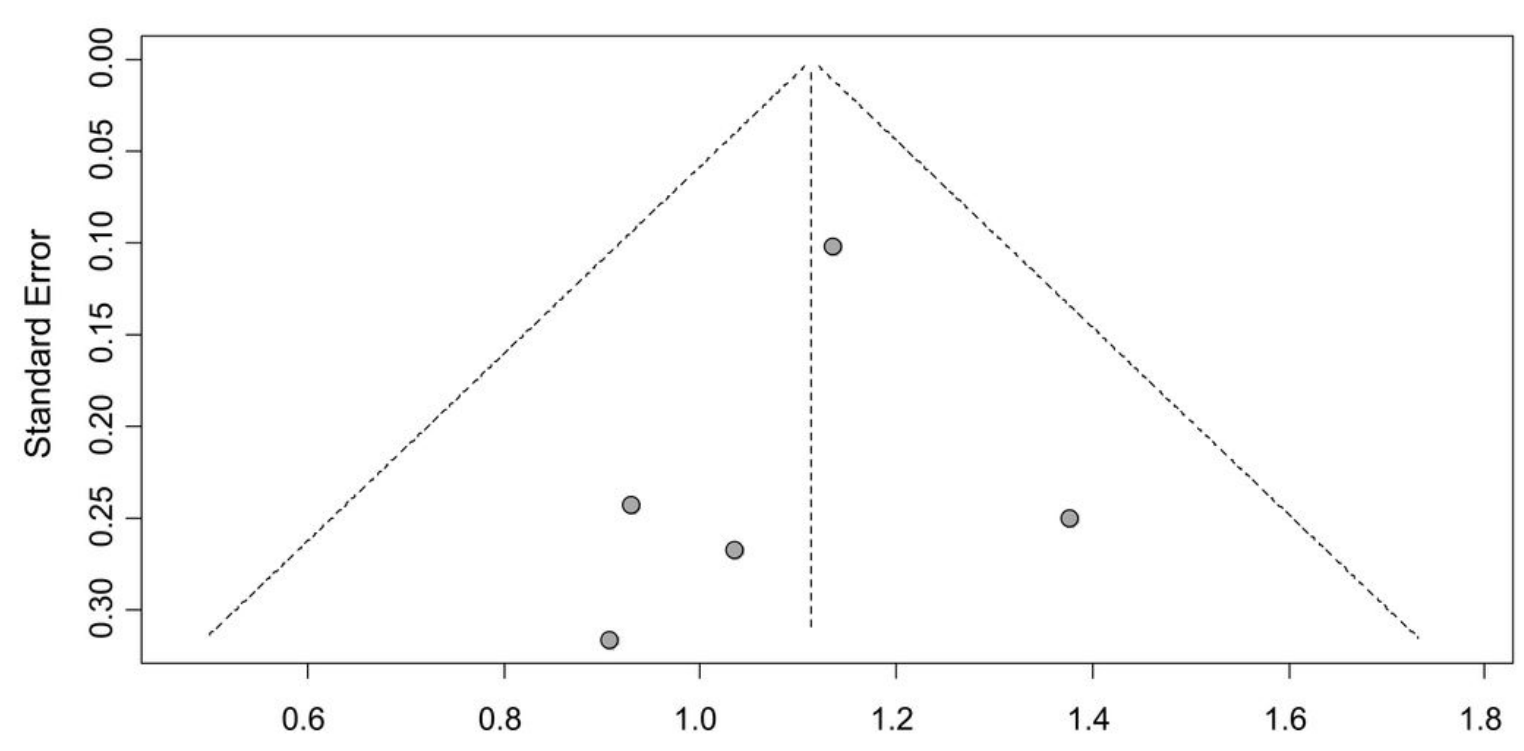

Fisher's z transformed correlation

Figure 4

Linear regression test of funnel plot asymmetry for identifying publication bias Abbreviations: 6MWT, 6-minute walk test; peak V02, peak oxygen uptake; ISWT, incremental shuttle walk test

\section{Supplementary Files}

This is a list of supplementary files associated with this preprint. Click to download.

- Additionalfile1.doc

- Additionalfile2.tif

- Additionalfile3.tif 